\title{
Association of Some Socio-Dermographic Factors with Seminal Fluid Parameters in Ilorin, Nigeria: A Cross Sectional Study
}

\author{
N. Ugwueke Thaddeus ${ }^{1}$, Ibrahim Isa A. ${ }^{2,}$, Eugene M. Ikeanyi ${ }^{2}$ \\ ${ }^{1}$ George's Memorial Medical Centre, Lagos, Nigeria \\ ${ }^{2}$ Department of Obstetrics and Gynaecology, College of Health Sciences, Niger Delta University, Wilberforce Island, Nigeria
}

Email address:

daddayzee@yahoo.com (Ibrahim I. A.)

${ }^{*}$ Corresponding author

\section{To cite this article:}

N. Ugwueke Thaddeus, Ibrahim Isa A., Eugene M. Ikeanyi. Association of Some Socio-Dermographic Factors with Seminal Fluid Parameters in Ilorin, Nigeria: A Cross Sectional Study. Clinical Medicine Research. Vol. 5, No. 6, 2016, pp. 91-95. doi: 10.11648/j.cmr.20160506.11

Received: December 25, 2016; Accepted: January 9, 2017; Published: February 22, 2017

\begin{abstract}
Several factors affect seminal fluid indices, these factors impair male fertility either by exerting a gonadotoxic effect on the testicles, altering hypo-thalamic-pituitary-gonadal axis, impairing ejaculation and erectile function or by decreasing libido. The Study aim to assess the effects of some adverse socio-dermographic factors on seminal parameters of infertile couples. Three hundred and nine (309) male partners of infertile couples were recruited from five different fertility centers in Ilorin, Kwara state Nigeria using multi-stage sampling technique. Those with abnormal seminal fluid indices represented the study arm while those with normal semen indices represented the control arm for the study. Seminal fluid analysis was conducted on each participant and compared with World Health Organization reference for normal semen parameters. The results showed that male partners of infertile couples with abnormal seminal fluid indices had increased pattern of risky sexual behavior, with more numbers of both current sexual partners and life-time sexual partners, in addition to history of alcohol intake and cigarette smoking. (All $\mathrm{P}<0.05$ ). However, no statistical significant association was obtained with the amount of alcohol use, number of cigarette smoked and the use of native medication. Risky sexual behaviours, alcohol intake and cigarette smoking still remain important risk factors for abnormal seminal fluid indices. Thus, it is important to reeducate and enlighten the populace on the risk posed by these adverse social factors.
\end{abstract}

Keywords: Alcohol, Demography, Male Infertility, Seminal Fluid Indices, Smoking

\section{Introduction}

Infertility as defined by the World Health Organization (WHO) is the inability of a couple of child bearing age to conceive over twelve months of exposure to regular unprotected sexual intercourse [1]. Infertility affects $8-12 \%$ of couples worldwide [1]. Its prevalence is $6 \%$ and $10 \%$ in the United Kingdom and United States of America respectively [2]. In sub-Saharan Africa, the prevalence of infertility is about $30-40 \%$ [2]. In Nigeria, the incidence of infertility varies from $20-30 \%$ [3].

Male factor infertility implies a lack of sufficient numbers of competent sperm, resulting in failure to fertilize the normal ovum [4]. Available evidence suggests that male fertility is an important but neglected reproductive health issue in Nigeria [4]. Published studies indicate that the male factor may be the cause of 20 to $70 \%$ of the cases of infertility in different parts of the country $[5,6]$.

Studies from several populations around the world indicate that smoking [7], type of occupation [8], alcohol and coffee intake [4] as well as nutritional factors [7] affect male fertility. Other factors include infections such as tuberculosis [8], which can directly or indirectly damage the male reproductive system. Several sexually transmitted infections such as Neisseria gonorrhea and Chlamydia trachomatis have been linked to reduced fertility because of reduced sperm functions [9]. There are reports indicating high rates of infertility among males attending sexually transmitted 
infection (STI) clinics in Nigeria [10]. Thus, it was relevant to assess the relationship between previous exposures to STIs and infertility amongst males in Ilorin, Nigeria. In addition, since the pattern of sexual behaviour has direct connection with the prevalence of STIs, the impact of polygamy and multiple sexual partners on semen quality and invariably on male infertility was also determined. Other risk factors that were equally important to investigate for their association with male infertility included previous exposure to drugs, smoking and alcohol, concurrent medical illnesses, surgical procedures such as hernia repair and use of native medications [11].

Seminal fluid analysis is an important laboratory diagnostic procedure because several abnormalities of semen production and quality have been identified in majority of cases $[4,12]$. These abnormalities include oligozoospermia, azoospermia, asthenozoospermia, teratozoospermia, necrozoospermia or a combination of these [13].

Few studies have been done on male infertility in Nigeria, but none had investigated the socio-demographic characteristics and clinical correlates of patients with normal and abnormal seminal fluid indices in Ilorin. Identifying the risk factors (if present) and their effects on seminal fluid indices can facilitate the management of these couples especially where these factors are treatable or modifiable.

\section{Participants and Methods}

This cross-sectional, multicentre descriptive study was carried out between 1st August and - 31st December 2011 in the University of Ilorin Teaching Hospital, Anchor Medical Centre, Royal Care Medical Centre, Surulere Medical Centre and Mid-Land Fertility Centre located in Ilorin, Kwara State, Nigeria.

The sample size was calculated using the formula $\mathrm{n}=$ $\mathrm{z}^{2} \mathrm{pq} / \mathrm{d}^{2}$ [14]. Where $\mathrm{n}=$ sample size for the study; $\mathrm{z}=$ standard normal deviation (a constant) which is 1.96 at $95 \%$ confidence interval; $\mathrm{p}=$ assumed prevalence $(20 \%)$ of male infertility; $q=1-p ; d=$ observed difference of $5 \%$ or more taken as being significant. The calculated sample size of 246 participants was obtained. However, with an assumed 10\% non-response rate or attrition the statistically acceptable minimum total sample size for the study was 271 participants.

All male patients that attended the fertility clinics during the period stated above were enrolled in the study. Systematic random sampling was used for the selection of participants, with every fourth participants being interviewed after obtaining their informed consent. seven research assistants who were selected doctors, one from each of the three units in the department of Obstetrics and Gynaecology in UITH as well as one for each of the other four centres, attending to the couples regularly in the Gynaecology Clinics, were trained and educated prior to administration of questionnaire with the study objectives and protocol in mind. Their duty was primarily to help recruit patients based on the study criteria for the researcher. These patients were later seen by the researcher who also carried out the clinical examination on these patients. Two laboratory scientists (research assistants) from the department of microbiology in UITH, were involved in carrying out the analysis of the semen samples.

Data were collected using a pre-tested semi-structured questionnaire that was adapted to the local situation.

COLLECTION AND ANALYSIS OF SEMEN: The standard WHO guideline for semen analysis was used [13]. The participants were instructed to abstain from sexual intercourse for three days before semen collection. The masturbation method was adopted for production of semen that was collected in a sterile wide-mouth container provided for the purpose. The container with semen was sent to the laboratory for analysis within 30 minutes of collection.

Statistical analysis of the data was performed with Epiinfo version 6.0 software packages where nominal data were compared using the chi square test and the difference between means determined by the students $t$ - test with the level of significance set at $\mathrm{p}<0.05$.

ETHICAL CONSIDERATION: Approval of this study was obtained from the ethical committee of the University of Ilorin Teaching Hospital, Ilorin. Permission to use other study sites was obtained from constituted authorities. The study was explained to each of the selected participants and their informed consent, which was documented, obtained before being included in the study.

\section{Results}

During the period of the study, a total of 309 male partners of infertile couples were recruited for the study; 139 (45.0\%) had abnormal semen parameters while 170 (55.0\%) had normal semen parameters representing the subject and the control groups respectively.

Table 1 depicts the socio-demographic characteristics of the participants where there was no statistically significant difference in the age distribution $(\mathrm{t}=1.57, \mathrm{p}=0.1173)$, the religion $\left(\mathrm{x}^{2}=0.43 ; \mathrm{df}=1 ; \mathrm{p}=0.5135\right)$, ethnicity $\left(\mathrm{x}^{2}=2,11\right.$; $\mathrm{df}=3 ; \mathrm{p}=0.5507)$ and educational level $\left(\mathrm{x}^{2}=2.51 ; \mathrm{df}=3 ; \mathrm{p}\right.$ $=0.4735)$ of the participants. Majorities were between 30 years to 40 years $(57.2 \%)$, Muslims $(56.9 \%)$, of the Yoruba ethnic group $(89.6 \%)$ and with tertiary level of education $(67.9 \%)$. There was however a statistically significant difference in type of family $\left(\mathrm{x}^{2}=7.14 ; \mathrm{df}=1 ; \mathrm{p}=0.0075\right)$ where more of the subjects were polygamous (19.4\%).

The patterns of semen abnormality obtained from the participants are shown on Table 2. Among the study group, $49.6 \%$ had asthenozoospermia, which represents the commonest semen abnormality; oligozoospermia accounted for $41 \%$ of semen abnormality, and Teratozoospermia was the least common semen abnormality with $9.4 \%$ incidence.

The reported patterns of sexual activity of the participants are presented on Table 3 . Most of the participants in the study group (51.8\%) had sexual intercourse twice a week. Majority $(70.5 \%)$ of them also had more than one current sexual partner as against $(57.1 \%)$ of participant in the control group. 
In addition, having more than three life time sexual partners was more common among participants in the study group compared to those in the control $(4.3 \%$ vs $0.6 \%)$ and this difference was statistically significant ( $\mathrm{p}$ value- 0.0355 ).

Table 4 compared the participants in the study and control groups based on their medical history: hypertension, diabetes mellitus and sickle cell disease. History of hypertension and diabetes mellitus showed a significant correlation with abnormal seminal fluid indices.

Table 5 compared the pattern of smoking between participants in the study and the control groups. Smoking was shown to be a significant risk factor with a p-value of 0.0001 . However, the severity of smoking as shown by the number of sticks of cigarette smoked was not statistically significant (p-0.6454).

Table 6 compared the pattern of Alcohol intake among the participants. Alcohol intake was shown to be a significant risk factor for abnormal seminal fluid indices (p-0.0003). However, the amount of alcohol intake was not statistically significant $(\mathrm{p}=0.0889)$

Table 1. Socio-demographic characteristics of participants.

\begin{tabular}{|c|c|c|c|}
\hline Variable & Study Group & Control & p-value \\
\hline \multicolumn{4}{|l|}{ Age group (years) } \\
\hline$\leq 30$ & $20(14.4)$ & $13(7.6)$ & \multirow{7}{*}{$\begin{array}{l}\mathrm{t}=-1.57 \\
\mathrm{p}=0.1173\end{array}$} \\
\hline $30-35$ & $50(36.0)$ & $45(26.5)$ & \\
\hline $36-40$ & $36(25.9)$ & $46(27.1)$ & \\
\hline $41-45$ & $20(14.4)$ & $42(24.7)$ & \\
\hline $46-50$ & $13(9.4)$ & $14(8.2)$ & \\
\hline$>50$ & $7(5.0)$ & $10(5.9)$ & \\
\hline Mean \pm SD & $37.91 \pm 7.32$ & $39.18 \pm 6.75$ & \\
\hline \multicolumn{4}{|l|}{ Educational level } \\
\hline None & $5(3.6)$ & $3(1.8)$ & \multirow{4}{*}{$\begin{array}{l}X^{2}=2.51 \\
d f=3 \\
p=0.4735\end{array}$} \\
\hline Primary & $14(10.1)$ & $11(6.5)$ & \\
\hline Secondary & $28(20.1)$ & $38(22.4)$ & \\
\hline Tertiary & $92(66.2)$ & $118(69.4)$ & \\
\hline \multicolumn{4}{|l|}{ Occupation } \\
\hline Manager & $5(3.6)$ & $2(1.2)$ & \multirow{12}{*}{$\begin{array}{l}X^{2}=16.46 \\
d f=8\end{array}$} \\
\hline Professional & $34(24.5)$ & $29(17.1)$ & \\
\hline Clerical support workers & $20(14.4)$ & 39 (22.9) & \\
\hline Service \& sales workers & $25(18.0)$ & $37(21.8)$ & \\
\hline Skilled agricultural, & $\mathrm{p}=0.0362$ & & \\
\hline Forestry \& fishery workers. & $2(1.4)$ & $8(4.7)$ & \\
\hline Craft \& related trade workers & $24(17.3)$ & $37(21.8)$ & \\
\hline \multicolumn{3}{|l|}{ Plant \& machine operators } & \\
\hline$\&$ assemblers & $7(5.0)$ & $5(2.9)$ & \\
\hline Elementary occupation & $19(13.7)$ & $12(7.1)$ & \\
\hline Armed forces & $3(2.2)$ & $1(0.6)$ & \\
\hline Total & $139(100.0)$ & $170(100.0)$ & \\
\hline \multicolumn{4}{|l|}{ Ethnicity } \\
\hline Yoruba & $123(88.5)$ & $154(90.6)$ & \multirow[b]{2}{*}{$\mathrm{X}^{2}=2.11$} \\
\hline Ibo & $9(6.5)$ & $8(4.7)$ & \\
\hline Hausa & $4(2.9)$ & $2(1.2)$ & $\mathrm{df}=3$ \\
\hline Others $* *$ & $3(2.1)$ & $6(3.5)$ & $\mathrm{p}=0.5507$ \\
\hline \multicolumn{4}{|l|}{ **Edo, Ebira and Nupe } \\
\hline \multicolumn{4}{|l|}{ Religion } \\
\hline Islam & $82(59.0)$ & $94(55.3)$ & \multirow{2}{*}{$\begin{array}{l}X^{2}=0.43 \\
d f=1 \\
p=0.5135\end{array}$} \\
\hline Christianity & $57(41.0)$ & $76(44.7)$ & \\
\hline \multicolumn{4}{|l|}{ Family type } \\
\hline Monogamy & $127(91.4)$ & $137(80.6)$ & $X^{2}=7.14$ \\
\hline Polygamy & $12(8.6)$ & $33(19.4)$ & $\begin{array}{l}\mathrm{df}=1 \\
\mathrm{p}=0.0075\end{array}$ \\
\hline
\end{tabular}

Table 2. Pattern of semen abnormality.

\begin{tabular}{llll}
\hline Variable & Study Group & Control & p-value \\
\hline $\begin{array}{l}\text { Sperm count } \\
\text { Total sperm count } \\
\text { abnormality }\end{array}$ & & & \\
Azoospermia & $18(12.9)$ & $0(0.0)$ & \\
Severe Oligozoospermia & $47(33.8)$ & $0(0.0)$ & \\
Oligozoospermia & $57(41.0)$ & $0(0.0)$ & \\
Normal & $17(12.2)$ & $170(0.0)$ & $\mathrm{p}=0.0000$ \\
Motility & & & \\
Asthenozoospermia & $69(49.6)$ & $0(0.0)$ & \\
Normal & $70(50.4)$ & $170(0.0)$ & $\mathrm{p}=0.0000$ \\
Morphology & & & \\
Teratozoospermia & $13(9.4)$ & $0(0.0)$ & \\
Normal & $126(90.6)$ & $170(100.0)$ & $\mathrm{p}=0.0004$ \\
\hline
\end{tabular}

Table 3. Sexual activity in study subjects.

\begin{tabular}{llll}
\hline Frequency par week & Study Group & Control & p value \\
\hline 1 & $25(18.0)$ & $29(17.1)$ & \\
2 & $72(51.8)$ & $59(34.7)$ & $\mathrm{X}^{2}=11.52$ \\
3 & $24(17.3)$ & $47(27.6)$ & $\mathrm{df}=4$ \\
4 & $13(9.4)$ & $26(15.3)$ & $\mathrm{p}=0.0213$ \\
Not stated & $5(3.6)$ & $9(5.3)$ & \\
Number of current & & & \\
sexual partners & & $73(42.9)$ & \\
1 & $41(29.5)$ & $52(30.6)$ & $\mathrm{X}^{2}=12.00$ \\
2 & $63(45.3)$ & $34(20.0)$ & $\mathrm{df}=3$ \\
3 & $19(13.7)$ & $33(19.4)$ & $\mathrm{p}=0.0074$ \\
$>3$ & $16(11.5)$ & & \\
Number of life time & & & \\
sexual partners & & $122(71.8)$ & \\
1 & $81(58.3)$ & $41(24.1)$ & $\mathrm{X}^{2}=8.57$ \\
2 & $46(33.1)$ & $6(3.5)$ & $\mathrm{df}=3$ \\
3 & $6(4.3)$ & $1(0.6)$ & $\mathrm{p}=0.0355$ \\
$>3$ & $6(4.3)$ & $170(100.0)$ & \\
Total & $139(100.0)$ & & \\
\hline
\end{tabular}

Table 4. Medical History.

\begin{tabular}{llll}
\hline Variables & Study Group & Control & p value \\
\hline $\begin{array}{l}\text { Hypertension } \\
\text { Yes }\end{array}$ & $26(18.7)$ & $17(10.0)$ & $\mathrm{p}=0.0278$ \\
No & $113(81.3)$ & $153(90.0)$ & \\
Diabetes Mellitus & & & \\
Yes & $11(7.9)$ & $4(2.4)$ & $\mathrm{p}=0.0458$ \\
No & $128(92.1)$ & $166(97.6)$ & \\
Sickle cell Disease & & & \\
Yes & $4(2.9)$ & $0(0.0)$ & $\mathrm{p}=0.3997$ \\
No & $135(97.1)$ & $170(100.0)$ & \\
\hline
\end{tabular}

Table 5. History of cigarette smoking.

\begin{tabular}{llll}
\hline Cigarette smoking & Study Group & Control & p-value \\
\hline Yes & $31(22.3)$ & $12(7.1)$ & $\mathrm{X}^{2}=14.83$ \\
No & $108(77.7)$ & $158(92.9)$ & $\mathrm{df}=1$ \\
Total & $139(100.0)$ & $170(100.0)$ & $\mathrm{p}-0.0001$ \\
Severity of smoking & & \\
Quantity & & & $\mathrm{p}$-value \\
Mild & $22(15.8)$ & $10(5.9)$ & $\mathrm{X}^{2}=0.88$ \\
Moderate & $8(5.8)$ & $2(1.2)$ & $\mathrm{df}=2$ \\
Severe & $1(0.7)$ & $0(0.0)$ & $\mathrm{p}=0.6454$ \\
\hline
\end{tabular}


Table 6. History of alcohol intake.

\begin{tabular}{llll}
\hline Alcohol intake & Study group & Control & p-value \\
\hline Yes & $46(33.1)$ & $27(15.9)$ & $\mathrm{X}^{2}=112.55$ \\
No & $93(66.9)$ & $143(84.1)$ & $\mathrm{df}=1$ \\
$\begin{array}{l}\text { Total } \\
\text { degree of alcohol }\end{array}$ & $139(100.0)$ & $170(100.0)$ & $\mathrm{p}-0.0003$ \\
$\begin{array}{l}\text { intake } \\
\text { Variables }\end{array}$ & & \\
Standard & Study group & Control & $\mathrm{p}$-value \\
Moderate alcohol use & $10(7.1)$ & $12(7.1)$ & \\
Heavy alcohol use & $18(12.9)$ & $10(5.9)$ & $\mathrm{X}^{2}=6.52$ \\
Binge drinking & $13(9.4)$ & $5(2.9)$ & $\mathrm{df}=3$ \\
\hline
\end{tabular}

\section{Discussion}

The results showed that the commonest semen abnormality among the participants in the study group was asthenozoospermia accounting for $49.6 \%$ of abnormal seminal fluid indices in Ilorin at the time of this study. This is comparable to $44 \%$ reported at Onitsha [15] but less than $58.2 \%$ reported at Kano [16]. However, the percentage obtained for oligozoospermia in this study (46.7\%) was higher than that obtained at Onitsha [15]. The results showed a statistically significant difference in the pattern of reported sexual behaviour (i.e.; number of sexual partners and sexual frequency)_between the participants in the study and control groups.

The relationship between hypertension, diabetes mellitus and abnormal seminal fluid indices may be related to the vasculopathy which these medical diseases cause and as a result impair spermatogenesis and ejaculatory mechanism [17].

Cigarette smoking also showed a statistically significant association with abnormal seminal fluid indices in this study. This was however, independent of the number of sticks of cigarette smoked, this is contrary to published findings in other populations $[6,17,19$, and 20] but similar to the result obtained in Benin [11]. The difference in this result may be due to the fact that it was based on self- reporting as these patients may have been modest in their answers to the number of sticks of cigarette smoked.

The results showed a statistically significant association between abnormal seminal fluid indices and alcohol intake but not with the amount of alcohol consumed (moderate to heavy) alcohol intake. This is contrary to the results from other populations, which showed a link between moderate to heavy alcohol intake and male infertility [7, 11]. The mechanism underlying this relationship may not be totally clear but has been ascribed to the resultant decrease in serum testosterone concentrations and the resultant effect on spermatogenesis [11]. There may also be impairment in spinal reflexes reducing sensation and innervations of the penis and this may contribute to erection dysfunction [21]. However, the hypothesis which states that moderate to heavy alcohol intake may be a consequence of male remaining infertile [10] and not necessarily a causative factor of abnormal seminal fluid indices could be the reason for the result obtained in the present study. The fact that the present study was based on self-reporting may explain the discrepancy in the results as most of these participants may have been modest in their answers to the quantity of alcohol they consumed.

Other important associations obtained from the study were from occupational type. Managers, senior officials, professionals and technicians were more likely to have abnormal seminal fluid indices. This was similar to the results in other studies $[6,7]$. The reason for this may not be unrelated to their work demand and exposure to harmful agents such as electromagnetic field. It may also be as a result of their financial capability which indirectly influences their sexual habits and puts them at risk for STIs. Abnormal seminal fluid indices were also commoner in the elementary workers group, i.e.; office attendants and labourers. For this group of workers, it may be a reflection of their health seeking capacity which may be related to their low socioeconomic status.

\section{Conclusion}

The result of this study showed association between pattern of reported sexual behaviour and abnormal seminal fluid indices. Alcohol intake and cigarette smoking were also important risk factors for abnormal seminal fluid indices. This study however, did not show any statistically significant association between moderate and heavy alcohol intake as well as with the number of cigarette smoked. Thus, social life style still remains an important risk factor for health status and in this case, the quality of seminal fluid an individual produces.

\section{References}

[1] Audu BM, Massa AA, Bukar M. Clinical presentation of infertility in Gombe, North Eastern Nigeria. Trop J ObstetGynaecol 2003; 20 (2): 93-96.

[2] Etuk SJ. Reproductive health: Global infertility trend. Niger J PhysiolSci 2009; 24 (2): 85-90.

[3] Otubu JAM: Infertility. In: Agboola A (ed). Textbook of Obstetrics and Gynaecology for medical students, 2nd edition. Name of town Heinemann Educational Books (Nig) Plc, 2006; 123-133.

[4] Idrisa A, Ojiyi E. Pattern of infertility in North Eastern Nigeria. Trop J ObstetGynaecol 2000; 17: 27-29.

[5] Esimai OA, Orji EO, Lasisi AR. Male contribution to infertility in Ile-Ife, Nigeria. Niger J Med 2002, Apr-Jun; 11 (2): 70-72.

[6] Chia SE, Lim ST, Tay SK. Factors associated with male infertility: a case control study of 218 infertile and 240 fertile men. Br J ObstetGynaecol 2000; 107 (1): 55-61.

[7] Chia SE, Tay SK. Occupational risk factors for male infertility: a case-control study of 218 infertile and 227 fertile men. J Occup Environ Med 2001; 43 (11): 946-951. 
[8] Kumar R. Reproductive tract tuberculosis and male infertility. India J Urol. 2008 Jul- Sep; 24 (3): 392-395.

[9] Ajayi AB, Ogundepo MO, Oladokun A, Marhasson-Bello IO. Asymptomatic chlamydial infection and semen quality among Nigerian men. Trop J ObstetGynaecol 2004; 21 (suppl 1): 392-395.

[10] Nwabuisi C, Onile BA. Male infertility among STDs clinic attendees in Ilorin, Nigeria. Niger J Med 2001; 10 (2): 68-71.

[11] Okonofua F, Omo-Aghoja LO, Menakaya U, Onemu SO, Bergstrom S. A case control study for the risk factors for male infertility in Southern Nigeria. Trop J ObstetGynaecol 2005; 22 (2): 136-14

[12] Idrisa A, Ojiyi E, Tomfafi O, Kamara TB, Pindiga HU. Male contribution to infertility in Maiduguri, Nigeria. Trop J ObstetGynaecol, 2001; 18 (2): 87-90

[13] Cooper et al. WHO reference values for human semen characteristics. Human Reproduction Update 2010; 16 (3): 231-245.

[14] Araoye MO, Sample size determination. In: Araoye MO (Ed.). Research methodology with statistics for health and social sciences. Nathadex publishers Ilorin. 2003: 115-121

[15] Obiechina NJ, Okoye RN, Emelife EC. Seminal fluid indices of men attending infertility clinic at St. Charles Borromeo Hospital Onitsha, Nigeria (1994-1998). Niger J Med 2002 Jan-Mar; 11 (1): 20-22.

[16] Emokpae MA, Uadia PO, Sadiq NM. Contribution of bacterial infection to male infertility in Nigerians. Online $\mathrm{J}$ Health Allied Scs. 2009; 8 (1): 6.

[17] Ameh AB. Varicocelectomy: A predictable treatment of male infertility. Trop J ObstetGynaecol 2004; 21 (suppl 1): S40.

[18] Semen quality - Wikipedia; the free encyclopedia. Available at: http://en.wikipedia.org/wiki/semen_quality. Accessed $4 / 10 / 12$.

[19] Hassa H, Yildirim A, Can C, Turgut M, Tanir HM, Senses T, et al. Effect of smoking on semen parameters in men attending an infertility clinic. ClinExpObstetGynaecol 2006; 33 (1): 1922.

[20] Collodel G, Capitani S, Pammolli A, Giannerini V, Geminiani M, Moretti E. Semen quality of male idiopathic infertile smokers and non-smokers: an ultrastructural study. J Androl 2010 Mar-Apr; 31 (2): 108-113.

[21] Pasqualotto FF, Lucon AM, Sobreiro BP, Pasqualotto EB, Arap S. Effects of medical therapy, alcohol, smoking and endocrine disruptors on male infertility. Rev HospClin (On line) 2004; 59 (6): 375-382. Check pages. 